\title{
Inflammatory and neurohormonal modulation for congenital heart surgery: The quest continues
}

\author{
Saul Flores, MD, and Paul A. Checchia, MD, FCCM, FACC
}

\footnotetext{
From the Sections of Critical Care and Cardiology, Department of Pediatrics, Baylor College of Medicine, Texas Children's Hospital, Houston, Tex.

Disclosures: Authors have nothing to disclose with regard to commercial support.

Received for publication June 5, 2018; revisions received June 5, 2018; accepted for publication June 5, 2018; available ahead of print July 11, 2018

Address for reprints: Paul A. Checchia, MD, FCCM, FACC, Baylor College of Medicine, Cardiovascular Intensive Care Unit, Texas Children's Hospital, Section of Critical Care Medicine, 6651 Main St, MC: E1420, Houston, TX 77030 (E-mail: checchia@bcm.edu).

J Thorac Cardiovasc Surg 2018;156:1207-8

$0022-5223 / \$ 36.00$

Copyright (c) 2018 by The American Association for Thoracic Surgery

https://doi.org/10.1016/j.jtcvs.2018.06.004
}

Cardiopulmonary bypass (CPB) and deep hypothermic circulatory arrest (DHCA) elicit various biochemical, hemodynamic, and hormonal changes that may contribute to the development of different hemodynamic profiles in children undergoing heart surgery. The proinflammatory environment that exists after CPB and DHCA has been a target for different therapeutic interventions. Hormonal manipulation has been attempted as a means of positively affecting postoperative course. For example, the perioperative administration of corticosteroids is known to cause cellular membrane stabilization, reduction of HLA antigen upregulation, and inhibition of cytokine elaboration. Similarly, thyroid hormone modifies metabolic, immune, and cardiovascular functions and has been administered perioperatively as an optimizing agent to offset its relative reduction after $\mathrm{CPB}$ and DHCA.

In this issue of The Journal of Thoracic and Cardiovascular Surgery, Talwar and colleagues ${ }^{1}$ report a doubleblind, placebo-controlled trial in 100 infants with normal thyroid function. Subjects underwent cardiac surgery and were randomly assigned during a 16-month period into 2 groups (50 in the thyroxine supplementation group and 50 in the placebo group) to determine whether there was an association between oral thyroxine $\left(\mathrm{T}_{4}\right)$ supplementation and changes in cardiac index (CI), along with other important outcomes. Subjects in the study group received an oral dose of $5 \mu \mathrm{g} / \mathrm{kg}$ of $\mathrm{T}_{4}$ starting 12 hours before surgery and every morning thereafter while in the intensive care unit. Subjects in the study group had higher CI than did the placebo group (CI $0.30 \mathrm{~L} / \mathrm{min} / \mathrm{m}^{2}$ higher; $\left.P=.04\right)$. This association remained significant in the group versus time interaction analysis (CI $0.53 \mathrm{~L} / \mathrm{min} / \mathrm{m}^{2}$ higher; $95 \%$ confidence interval, $\left.0.30-0.76 \mathrm{~L} / \mathrm{min} / \mathrm{m}^{2} ; P<.0001\right)$. Subjects were also stratified into simple and complex categories according to congenital heart lesion and postoperative course for further analysis. Subjects in the complex group who received $\mathrm{T}_{4}$ required shorter duration of mechanical ventilation (study group, $3.85 \pm 0.92$ days

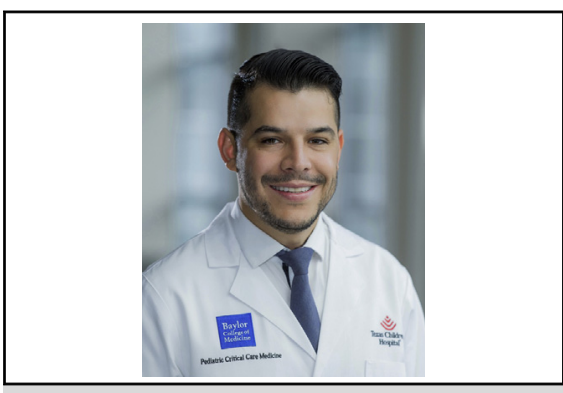

Saul Flores, MD

Central Message

Perioperative oral thyroxine may improve outcomes in children undergoing cardiac surgery. Preoperative and postoperative tools are needed to identify the most susceptible patients for optimal therapy.

See Article page 1209.

vs placebo, $4.66 \pm 1.55$ days; $P=.001$ ), shorter ICU stay (study group, $6.79 \pm 2.26$ days vs placebo, $8.30 \pm 33.09$ days; $P=.03)$, and lower inotropic scores (6.7 less; 95\% confidence interval, 2.7-0.7; $P<.0001)$. In addition, Talwar and colleagues ${ }^{1}$ found that the interleukin 6 levels were reduced a long as 24 hours in subjects in the study group $(P<.001)$.

It has been well described that early after the initiation of CPB, particularly DHCA, thyroid-stimulating hormone concentration is raised, responding to decreased concentrations of triiodothyronine $\left(\mathrm{T}_{3}\right)$, and that levels restore during a period of days, beginning with thyroidstimulating hormone and followed by $\mathrm{T}_{3}$, an entity referred as "euthyroid sick syndrome." 2 An actual etiology for these changes has not been precisely described; however, hemodilution, hypothermia, and inflammation have been implicated. ${ }^{3}$ As of now, thyroid hormone supplementation remains the mainstay therapy for euthyroid sick syndrome. This study of Talwar and colleagues, ${ }^{1}$ like several others, demonstrates that perioperative thyroid hormone supplementation is associated with improved outcomes. Recent studies have also demonstrated the hemodynamic benefits of oral $\mathrm{T}_{3}$ after CPB. ${ }^{6,7}$ To our knowledge, this is the first study to use oral $\mathrm{T}_{4}$ successfully in this setting. The results of this study are fascinating for several reasons. First, there are no pharmacokinetic studies demonstrating nearly similar bioavailability between $T_{4}$ 
(prohormone) and $\mathrm{T}_{3}$ (active hormone). The finding of increased $\mathrm{T}_{3}$ and $\mathrm{T}_{4}$ levels at all time points, even as early as 24 hours after surgery in the treatment group, is therefore distinctive. Second, most study subjects were infants younger than 4 months of age, and the dosing guidelines would recommend 6 to $8 \mu \mathrm{g} / \mathrm{kg}$ of $\mathrm{T}_{4}$ for this age group; however, beneficial effects were seen at a lower dose in this study. Third, there were significant interleukin 6 and tumor necrosis factor $\alpha$ elevation in the placebo group relative to the treatment group, indicating a potential anti-inflammatory effect of $\mathrm{T}_{4}$.

Some caution should be exerted in the interpretation and implementation of the results of Talwar and colleagues, ${ }^{1}$ because some limitations to this study were identified. It would have been beneficial to report objectively the nutritional status of subjects in this study, because it is essential for thyroid hormone hemostasis. Because of the intrinsic inotropic effect of thyroid hormone, the vasoactive inotropic score may not be a precise outcome measure in subjects receiving thyroid hormones. The measurement of cardiac output with transcutaneous monitors in infants has not been extensively validated. CI differences of $0.5 \mathrm{~L} / \mathrm{m} / \mathrm{m}^{2}$ thus may be clinically negligible under most given circumstances.

Another important cautionary note from the interpretation of these results must be highlighted. The current treatment of children with congenital heart disease provides outstanding postoperative care with short ventilation times, short length of stay, and low mortality in most clinical circumstances. The presence of some morbidities, such as euthyroid sick syndrome, still persists in certain patients, however, and provides an opportunity for individualized care. In this day and age, it has become increasingly evident that patient-specific characteristics must guide decision making for the initiation of therapies. As an example, corticosteroid use has become widespread for pediatric cardiac surgical patients without a firm grasp of individualized patient characteristics and incomplete outcome measurements. ${ }^{8,9}$ Consequently, we as a field must resist the temptation of universal administration of a particular therapy. This is particularly important because neurohormonal axis manipulation may present an unknown number of risks in this young, developing population. We must rather focus on careful preoperative and postoperative phenotyping to identify completely the optimal therapy for these patients.

\section{References}

1. Talwar S, Bhoje A, Khadagawat R, Chaturvedi P, Sreenivas V, Makhija N, et al. Oral thyroxin supplementation in infants undergoing cardiac surgery: a doubleblind placebo-controlled randomized clinical trial. J Thorac Cardiovasc Surg. 2018; $156: 1209-17$

2. Holland FW II, Brown PS Jr, Weintraub BD, Clark RE. Cardiopulmonary bypass and thyroid function: a "euthyroid sick syndrome" Ann Thorac Surg. 1991;52: 46-50.

3. Batra YK, Singh B, Chavan S, Chari P, Dhaliwal RS, Ramprabu K. Effects of cardiopulmonary bypass on thyroid function. Ann Card Anaesth. 2000;3: 3-6.

4. Portman MA, Slee A, Olson AK, Cohen G, Karl T, Tong E, et al; TRICC Investigators. Triiodothyronine supplementation in infants and children undergoing cardiopulmonary bypass (TRICC): a multicenter placebo-controlled randomized trial: age analysis. Circulation. 2010;122(11 Suppl):S224-33.

5. Mackie AS, Booth KL, Newburger JW, Gauvreau K, Huang SA, Laussen PC, et al. A randomized, double-blind, placebo-controlled pilot trial of triiodothyronine in neonatal heart surgery. J Thorac Cardiovasc Surg. 2005;130:810-6.

6. Marwali EM, Budiwardhana N, Prakoso R, Fakhri D, Boom CE, Djer MM, et al. Oral triiodothyronine supplementation decreases time to extubation after pediatric open heart surgery in Indonesia. Circulation. 2015;132:A11665.

7. Marwali EM, Boom CE, Budiwardhana N, Fakhri D, Roebiono PS, Santoso A, et al. Oral triiodothyronine for infants and children undergoing cardiopulmonary bypass. Ann Thorac Surg. 2017;104:688-95.

8. Pasquali SK, Hall M, Li JS, Peterson ED, Jaggers J, Lodge AJ, et al. Corticosteroids and outcome in children undergoing congenital heart surgery: analysis of the pediatric health information systems database. Circulation. 2010; 122:2123-30.

9. Checchia PA, Bronicki RA, Costello JM, Nelson DP. Steroid use before pediatric cardiac operations using cardiopulmonary bypass: an international survey of 36 centers. Pediatr Crit Care Med. 2005;6:441-4. 